\title{
Ventriculo-bipleural shunt as last resort in a 4-year-old child in whom a VP and VA shunt failed
}

\author{
Miriam Ratliff, MD, Andreas Unterberg, MD, Prof, and Heidi Bächli, MD, Prof \\ Department of Neurosurgery, Heidelberg University, Heidelberg, Germany
}

The authors present the unusual case of a 4-year-old boy who had a complex history of posthemorrhagic hydrocephalus and who underwent more than 40 surgeries related to this condition. In the course of trying to treat his condition, ventriculoperitoneal, ventriculoatrial, and ventriculopleural shunts were inserted and failed.

The child presented with a dysfunction of his shunt system. A ventriculopleural shunt was inserted, but within days the patient developed dyspnea as a clinical symptom of pleural effusion that required repeated thoracentesis. A bipleural drainage system was inserted, and no relevant pleural effusions developed during the follow-up period.

Although the authors' experience is based on a single case, they do suggest bipleural drainage in patients with clinically relevant pleural effusions when the more common alternatives are not a good choice. Bipleural drainage might particularly be an option in children, who are prone to pleural effusion because of the smaller absorbing pleural surface. The authors reviewed the English-language literature on PubMed dating back to 1952. To their knowledge, this is the only published case in which a patient was treated with a ventriculo-bipleural shunt.

http://thejns.org/doi/abs/10.3171/2015.7.PEDS15218

KEY WORDS hydrocephalus; ventriculopleural shunt; pleural effusion

A RECENT study evaluated shunt dependency in extremely low birth weight infants weighing between 400 and 1000 g. ${ }^{1}$ Of the surviving children who were followed up, $33 \%$ had a history of intraventricular hemorrhage (IVH), with $13 \%$ having IVH of Grade III or IV. Remarkably only $3 \%$ of the children required placement of a shunt for posthemorrhagic hydrocephalus.

While a ventriculoperitoneal (VP) shunt is the gold standard for continuous extracranial drainage of CSF for all age groups, ventriculoatrial (VA) and ventriculopleural (VPL) shunts are used as backup devices when the peritoneal cavity is unaccommodating. A VPL shunt is rarely used because of its associated risks of respiratory failure.

Imbalance between the production of CSF and its absorption can lead to the formation of pleural effusion in patients with VPL shunts and on occasion produce symptoms. Here we describe a case in which VP and VA shunts failed in the past and a VPL shunt led to pleural effusions with respiratory distress.

\section{Case Report}

History

This male child was born prematurely at a gestational age of 25 weeks, with a birth weight $770 \mathrm{~g}$. He sustained an IVH and ventricular dilation of Grade III. A ventricular reservoir (Rickham) was placed that allowed intermittent ventricular access. When posthemorrhagic hydrocephalus developed, the reservoir was subsequently converted to a VA ${ }^{2}$ shunt. The postsurgery course was complex, with episodes of repetitive mechanical dysfunction and trapped fourth ventricle. Over the years he underwent numerous follow-up surgeries. The VA shunt was converted back into a VP shunt, with CSF draining into the atrium. The

ABBREVIATIONS IVH = intraventricular hemorrhage; VA = ventriculoatrial; VP = ventriculoperitoneal; $V P L=$ ventriculopleural.

SUBMITTED April 8, 2015. ACCEPTED July 13, 2015.

INCLUDE WHEN CITING Published online November 27, 2015; DOI: 10.3171/2015.7.PEDS15218. 
atrial catheter clotted several times, but the etiology of this clotting was never identified. Laboratory workup at the time ruled out an initially suspected thrombophilia.

\section{Presentation and Examination}

At the age of 4 the patient first presented to our hospital. He exhibited symptoms of increased intracranial pressure as he had repeatedly in the past. He was $112 \mathrm{~cm}$ tall and weighed $15.3 \mathrm{~kg}$, and his head circumference was $43.5 \mathrm{~cm}$ (microcephalus). The atrial catheter again became clotted and had to be externalized. There were no signs of infection. Having had multiple previous abdominal surgeries related to an atretic small gut, he had developed adhesions in the abdomen. He also suffered from multiple incidences of VA shunt clotting of unknown origin. The decision was made to place a programmable $\mathrm{VPL}^{3}$ shunt with drainage into the right pleural cavity.

\section{Neuroimaging Studies and Operative Treatments}

The day after the VPL surgery the patient was admitted to the intensive care unit due to progressive respiratory failure. Upon auscultation, the child exhibited a diminished vesicular murmur in the right hemithorax. A chest radiograph revealed a right pleural effusion.

Initially conservative measurements were instituted. The settings of the valve and the adjustable antisiphon device were modified such that less CSF would be drained. Despite this, the child developed progressive respiratory distress 4 days after surgery. Another chest radiograph showed a massive right-sided pleural effusion (Fig. 1). During thoracentesis, $500 \mathrm{ml}$ of transudative fluid was drained. Microbiological studies on the fluid remained negative. The patient required two more thoracentesis treatments, 1 week apart, for the recurrence of a large pleural effusion, and on each occasion $300-500 \mathrm{ml}$ of transudative fluid was removed. After increasing the pressure of the valve aperture (proGAV $10 \mathrm{~cm} \mathrm{H}_{2} \mathrm{O}$ and ProSA $24 \mathrm{~cm} \mathrm{H}_{2} \mathrm{O}$ [Miethke]) and repeated evacuation of the ef- fusion during the 1st month after VPL placement, the patient's clinical course was satisfactory for 6 months.

However, 6 months later, the boy was admitted to the intensive care unit again with worsening symptoms of respiratory distress. Chest radiography confirmed the clinically suspected right-sided pleural effusion. In an attempt to further reduce drainage of the CSF into the pleural cavity, the setting of the ProSA antisiphon device was increased gradually to $34 \mathrm{~cm} \mathrm{H}_{2} \mathrm{O}$. This adjustment was not tolerated by the patient, and symptoms of raised intracranial pressure followed.

The intraperitoneal space was reevaluated laparoscopically as a potential cavity for drainage. During this procedure, extensive adhesions were seen. The possibility of intraperitoneal placement of the distal shunt catheter was ruled out. The surgical approach to the intraperitoneal space was extended to a laparotomy to obtain better access to the abdominal cavity. The abdominal scar tissue involved all parts of the digestive tract and the peritoneal lining. We discussed the option of adhesiolysis, use of an adhesion barrier (SprayShield), and temporary external drainage of CSF. Due to the extensive scar tissue formation, we agreed that the abdominal cavity was not an option. We decided to place a second pleural catheter into the left pleural cavity with a Y-connector to increase the surface of resorption (Fig. 1).

While the patient lay supine, we accessed the previously placed shunt system subcutaneously above the clavicle. A Y-connector was interconnected after proximal flow was verified. A small incision was made in the left midaxillary line at the level of the 4-5 intercostal space between the 4th and 5th rib. A second distal tube was connected to the system subcutaneously. A combination of blunt-end dissection and monopolar electrocautery was used for intercostal thoracotomy. Approximately $20 \mathrm{~cm}$ of intrathoracic tubing was passed into the interpleural space. An immediate chest radiograph was obtained to rule out pneumothorax and to confirm correct positioning of the tubing.
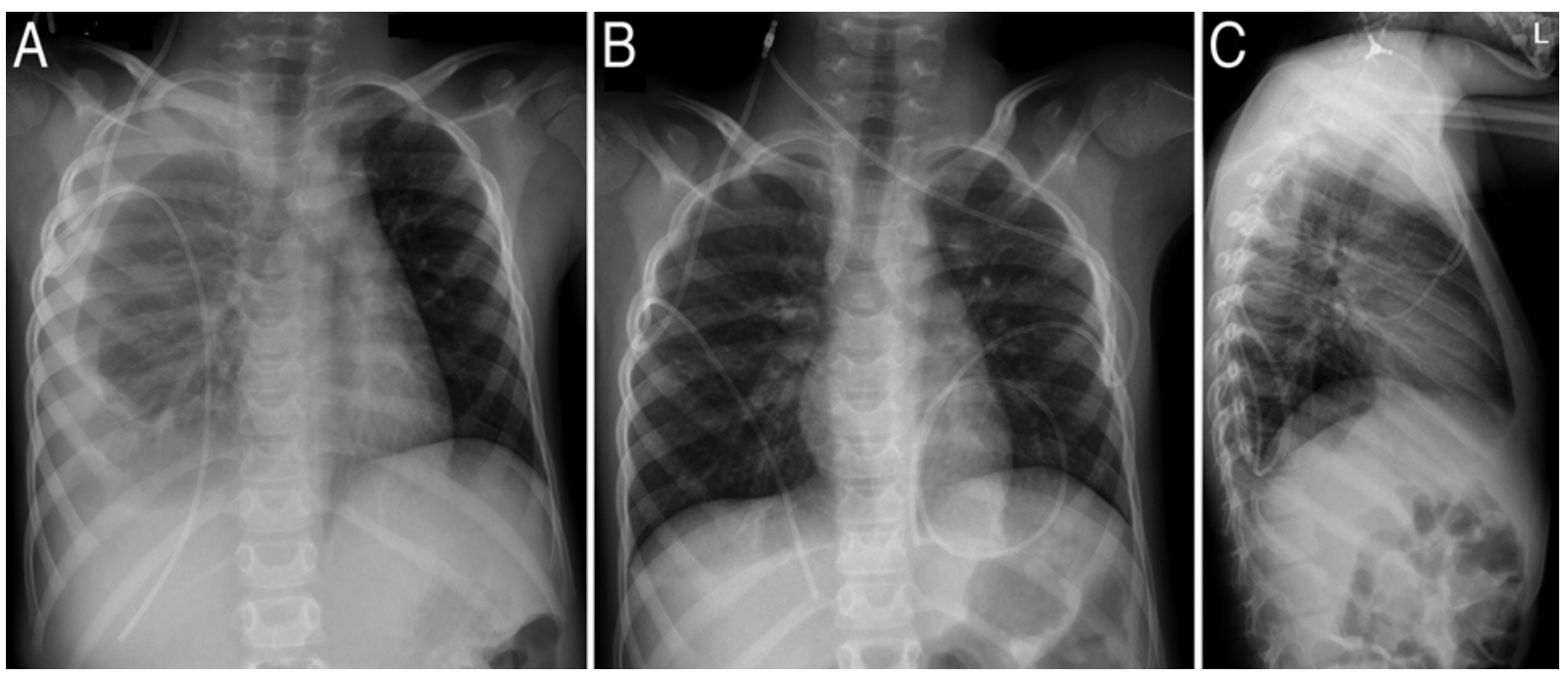

FIG. 1. Chest radiographs taken with the patient lying supine. Within days of placing a unilateral right-sided VPL shunt, a massive right pleural effusion was diagnosed (A). After connecting a secondary pleural catheter via interconnection of a Y-connector, no additional related pleural effusions were observed (B and $\mathbf{C}$ ). 


\section{Postoperative Course and Follow-Up}

After surgery, regular ultrasounds and chest radiographs were acquired to monitor for development of pleural effusions. In the following months, there was no need for pleural drainage, and the patient exhibited no signs of dyspnea.

In the 5-year follow-up period, the ventriculo-bipleural shunt device has remained in its original position. It is fully functional and has not led to any complications in terms of pleural effusions or respiratory distress. The patient's current valve settings are $12 \mathrm{~cm} \mathrm{H}_{2} \mathrm{O}$ and $28 \mathrm{~cm} \mathrm{H}_{2} \mathrm{O}$ for the proGAV and proSA devices.

\section{Discussion}

In patients with hydrocephalus, CSF can be drained from the ventricular system to various cavities in the body. Because of its technical simplicity and high efficacy, in addition to a lower rate of complications and their lesser severity, VP shunt surgery remains the procedure of choice for hydrocephalus. ${ }^{4} \mathrm{VP}$ shunts are preferred for most cases of hydrocephalus because of the large absorptive surface of the peritoneal lining and because of the accumulated experience of surgeons who frequently perform this procedure. However, a variety of abdominal conditions render the peritoneal cavity a suboptimal location for CSF diversion; these include adhesions due to prior major abdominal surgery, history of peritonitis, ascites, peritoneal dialysis, and failure of a prior VP shunt.

In the past VA shunts were also frequently used, but their popularity has been on the decline the past decade because of their association with 2 factors: 1) a significant morbidity and mortality rate due to thromboembolic complications and infections, and 2) an increased revision rate, particularly in children.

The use of the pleural cavity for drainage of CSF was first reported by Heile et al. in $1914^{4}$ and was than again mentioned by Ransohoff and Hiatt in 1952.11

In 1954, Ransohoff reported on a series of 6 patients with hydrocephalus in the context of midline tumors, which were successfully treated with a VPL shunt. He noted a good absorptive capacity of the pleura, and none of those patients developed pleural effusion. ${ }^{10}$

In a 1970 follow-up, involving 83 infants who were treated with a VPL shunt, Ransohoff and colleagues reported an overall success rate of $65 \%$. Patients ranged in age from 10 days to 18 months. A small number developed relevant pleural effusion. Although initially rewarding, the long-term results were less satisfactory. Shunt obstruction or pleural effusions frequently developed within 3 years. ${ }^{12}$

In 1978 Milhorat reported on 22 patients who ranged in age from 5 to 58 years and who had an average follow-up of 18 month. He recommended a medium-pressure Holter valve (Codman and Shurtleff) between ventricular and pleural catheter. Only one patient experienced pleural effusion. She had pulmonary emphysema. Milhorat recommended not using VPL shunts in children younger than 3 years of age or in patients with a lung disease. ${ }^{8}$

In 1962, Nixon expressed hope that differential pressure valves would reduce the incidence of pleural effusions. He reported on 3 patients treated with VPL shunts that had a differential pressure valve. ${ }^{9}$ However, Venes, despite using a differential pressure valve, reported that 6 patients had large effusions. ${ }^{13,14}$

In 1983 Hoffman et al. reviewed 59 cases of VPL shunting performed in children. They noted a pleural effusion-related complication rate of $20 \%$ (12 of 59 patients; 9 of the 12 were 5 years of age or younger). ${ }^{5}$

Venes reported a significantly higher pleural effusion rate in children, most likely due to a smaller pleural surface area leading to reduced absorption. ${ }^{13,14}$

Megison and Benzel, in 1988, conducted a retrospective study of 88 pleural shunting procedures. The patients ranged in age from 17 years to 88 years; 60 patients were males and 18 were females. The overall complication rate was $24 \%$ (21 of 88 operations), with $5 \%$ of complications due to relevant pleural effusion (4 of 88 operations). ${ }^{7}$

In 1988 Jones et al. reported on 29 children in whom a VPL shunt had been inserted from 1969 to 1979. Symptomatic pleural effusion developed in 18 patients. In only 7 infants did the VPL shunt remain functioning for more than 1 year. ${ }^{6}$

It is crucial for the proper functioning of a VPL shunt that the pleural surface absorb any accumulated fluid within the pleural cavity. Pleural fluid accumulates if the rate of CSF drainage and potential fluid formation in the pleural cavity exceeds the rate of absorption. Therefore, based on the reported literature and our experience, a VPL shunt is not the first choice for drainage in patients with hydrocephalus, particularly in children because the surface area capable of absorbing the liquid is much smaller than it is in adults. In our case the more frequently used bodily cavities such as atrium and peritoneum were not options. To increase the absorbing capacity of the pleural cavity, we placed a ventriculo-bipleural shunt. We also used an adjustable antigravity device and an adjustable pressure device to allow for maximum control of draining fluid.

Because the development of these pleural effusion can be gradual, routine and long-term follow-up examinations are required. To our knowledge, our case represents not only the only reported child but also the only reported patient who has been treated with a ventriculo-bipleural shunt as a surgical solution for recurring pulmonary distress due to pleural effusions.

\section{Acknowledgments}

We would like to thank Dr. Alfred Aschoff for suggesting bipleural drainage in this case.

\section{References}

1. Adams-Chapman I, Hansen NI, Stoll BJ, Higgins R: Neurodevelopmental outcome of extremely low birth weight infants with posthemorrhagic hydrocephalus requiring shunt insertion. Pediatrics 121:e1167-e1177, 2008

2. Carrion E, Hertzog JH, Medlock MD, Hauser GJ, Dalton HJ: Use of acetazolamide to decrease cerebrospinal fluid production in chronically ventilated patients with ventriculopleural shunts. Arch Dis Child 84:68-71, 2001

3. Hadzikaric N, Nasser M, Mashani A, Ammar A: CSF hydrothorax-VP shunt complication without displacement of a peritoneal catheter. Childs Nerv Syst 18:179-182, 2002

4. Heile B: Zur chirurgischen Behandlung des Hydrocephalus 
internus durch Ableitung der Cerebrospinalflüssigkeit nach der Bauchhöhle und nach der Pleurakuppe. Arch Klin Chir 105:105-116, 1914

5. Hoffman HJ, Hendrick EB, Humphreys RP: Experience with ventriculo-pleural shunts. Childs Brain 10:404-413, 1983

6. Jones RF, Currie BG, Kwok BC: Ventriculopleural shunts for hydrocephalus: a useful alternative. Neurosurgery 23:753755,1988

7. Megison DP, Benzel EC: Ventriculo-pleural shunting for adult hydrocephalus. Br J Neurosurg 2:503-505, 1988

8. Milhorat TH: Pediatric Neurosurgery. Philadelphia: FA Davis, 1978, pp 123-125

9. Nixon HH: Ventriculo-pleural drainage with a valve. Dev Med Child Neurol 4:301-302, 1962

10. Ransohoff J: Ventriculo-pleural anastomosis in treatment of midline obstructional neoplasms. J Neurosurg 11:295-298, 1954

11. Ransohoff J II, Hiatt RB: Ventriculo-peritoneal anastomosis in the treatment of hydrocephalus; utilization of the suprahepatic space. Trans Am Neurol Assoc 56 (77th Meeting): $147-151,1952$

12. Ransohoff J, Shulman K, Fishman RA: Hydrocephalus: a review of etiology and treatment. J Pediatr 56:399-411, 1960

13. Venes JL: Pleural fluid effusion and eosinophilia following ventriculo-pleural shunting. Dev Med Child Neurol 16:7276,1974

14. Venes JL, Shaw RK: Ventriculopleural shunting in the management of hydrocephalus. Childs Brain 5:45-50, 1979

\section{Disclosures}

The authors report no conflict of interest concerning the materials or methods used in this study or the findings specified in this paper.

\section{Author Contributions}

Conception and design: Ratliff. Analysis and interpretation of data: Bächli. Drafting the article: Ratliff. Critically revising the article: Unterberg, Bächli. Reviewed submitted version of manuscript: all authors. Approved the final version of the manuscript on behalf of all authors: Ratliff.

\section{Correspondence}

Miriam Ratliff, Department of Neurosurgery, Heidelberg University, Im Neuenheimer Feld 400, Heidelberg 69120, Germany. email: miriam.ratliff@med.uni-heidelberg.de. 